\title{
Selenium not for dumping
}

\section{California is up in arms because of selenium in some drinking water. Does it not know that selenium is also an essential dietary supplement?}

WHY do so many land animals depend so crucially on inorganic substances predominantly present only in sea water, selenium for example? The question has most recently been provoked by the fuss, in California, about the discovery last year of selenium in the water stored in the Kesterson reservoir. Officials of the city of Monterey have since refused to allow that supposedly toxic fluid to be allowed to return to the Pacific Ocean. In their ignorance, they have overlooked a question that is not merely of practical importance (how do we keep our people healthy?) but one that has profound significance for people everywhere - where did we come from?

This is how the tale goes. Life began in the oceans or shallow seas. The primitive enzyme systems depended on inorganic ions. (Physiologists have often remarked on the resemblance between body fluids and sea water.) But some of these vital inorganic substances are needed in only small amounts. These are the nutritionally essential trace minerals, such as iodine, molybdenum, manganese and zinc. When living organisms emerged from the oceans, animals and plants that became land-dwellers had to find soil that supplied these minerals. Iodine is uncommon except near the oceans. Plants do not need it, but goitre became an endemic disease of animals in inland areas lacking iodine.

Geological variations in the Earth's crust, glaciation during the great Ice Age, the effects of vulcanism and the results of erosion and leaching are some of the factors that decide which parts of the Earth's surface are either deficient or oversupplied with trace minerals.

In some parts of the world, most conspicuously in Australia, the soil is so deficient in certain trace minerals such as zinc and copper that plants will not grow. Elsewhere, soil contains a toxic excess of some minerals. One of these is selenium, which was known for many years only as being poisonous, even carcinogenic. It came into prominence because certain plants such as Astragalus (locoweed) concentrate it from high-selenium soils so that horses that eat Astragalus may become poisoned, or "locoed" ("blind staggers"). In the 1930s, Franke and his co-workers reported effects of "toxic wheat" grown in South Dakota on high-selenium soil.

Thomas H. Jukes is in the Department of Biophysics and Medical Physics at the University of California, Berkeley, California 94720, USA.
Feeding toxic wheat or selenium to hens produced deformed embryos in their eggs with eyes and beaks missing, and with distorted wings and feet ' . No such injuries were detected in human beings; the only bad effects noted were dental caries.

The bad reputation of selenium was abruptly changed in 1957, when it was found in laboratory studies to be a nutritionally essential trace element for rats, chickens and pigs ${ }^{2-4}$. This news was followed with startling rapidity by reports of selenium deficiency in farm animals all over the world, especially in New Zealand. Selenium provided one of the most dramatic illustrations of the rule of Paracelsus that "the dose alone determines the poison", a rule that seems to have been forgotten by most of us.

Among the many studies of the toxicity of selenium were some carried out by the US Food and Drug Administration (FDA) which led to the conclusion that high levels of selenium are carcinogenic ${ }^{5}$. Since official thinking does not permit the extension of Paracelsus' rule to carcinogens, FDA agonized for 15 years before it allowed selenium to be added to the diet of farm animals.

Ironically, selenium had meanwhile emerged as an anticarcinogen and as a component of an important enzyme, glutathione peroxidase, an enzyme important in the metabolism of injurious hydroperoxides ${ }^{6}$.

Now move to China, where multiple myocarditis, "Keshan disease", is found in children in populations with low levels of blood selenium living in low-selenium areas. Epidemiological studies show an inverse correlation between blood selenium and age-adjusted total cancer death rates and liver cancer incidence. In areas with high selenium levels, there is significantly lower mortality from cancer of the oesophagus and stomach. As a public health measure, a programme has been started of spraying grain crops with sodium selenite solution ${ }^{7}$. The difficulty may be that both the population and the food supply may be less mobile than in the United States.

In California (where anything can happen, and usually does), selenium leaching from the coastal foothills of central California (perhaps a result of acid rain) got into irrigation water and became concentrated in drainage reservoirs. Aquatic birds, coots and wild duck, living in the Kesterson reservoir, re-enacted in
1984 the 1930 drama of the South Dakota chickens, producing deformed offspring. Environmentalists sprang into action, saying that selenium would probably cause deformed human embryos. The headlines flared. Officials in Monterey acted. A former head of California Water Resources Control Board spoke of the "Kesterson nightmare", and predicted ${ }^{8}$ "another year's crop of what may very well be contaminated produce".

In reality, the "contaminated produce" is probably helping to protect consumers against cancer ${ }^{9.10}$. The permissible level of selenium in drinking water, set by the Environmental Protection Agency (EPA) at 10 parts per thousand million, should probably be raised to 50 to 100 parts per thousand million as a public health measure.

Until FDA gave approval for selenium as an animal feed additive, farmers literally had to return to the ocean, the original source of selenium for animals, to obtain selenium for their livestock. This was done by feeding fishmeal, the selenium in which was natural and therefore legal. Selenium has another role in ocean fish; it prevents the injurious action of mercury that is naturally present in seawater and is added to the ocean by volcanic discharge and run-off from coastal soils.

Various hearings on the disposition of the Kesterson water have brought forth recommendations ranging from stopping agriculture in the vicinity of Kesterson to skimming off the surface soil and burying it. In none of the hearings has the essential nature of selenium, or the fact that selenium is a natural resource that tends to be depleted and lost, been discussed or even mentioned. Nor have tolerable levels of intake been suggested. The objective seems to be to treat selenium as a toxicant that must be sequestered, yet much of the land in California and more in Oregon, is deficient in selenium. Shall we have to go back to the sea?

Thomas Jukes

1. Franke, K.W. \& Tully, W.C. Poultry Sci. 15, $316(1936)$

2. Schwarz, J. \& Foltz, C.M. J. Am. chem. Soc. 79, 3292 (1957).

3. Patterson, E.L. et al. Proc. Soc. exp. Biol. Med. 95, 617 (1957)

4. Eggert, R.G. et al. J. Anim. Sci. 6, 1031 (1957).

5. Nelson, A.A. et al. Cancer Res. , 230 (1943)

6. Rotruck, J.T. et al. Science 179, 38 (1973)

7. Yu, S-Y, et al. Biological Trac Element Research 7, 21 (1985).

8. Newdorf, D. Contra Costa Times, California (19 May 1985)p. 6B.

9. Sakurai, H. \& Tsuchiya, Y. Envir. Physiol. Biochem. 5, 107 (1975).

0. Schrauzer, G.N. Vitamins, Nutrition and Cancer, 240 (Karger, Basel 1984) 